\title{
The Jade Buddha for Universal Peace
}

\author{
David L. McMahan
}

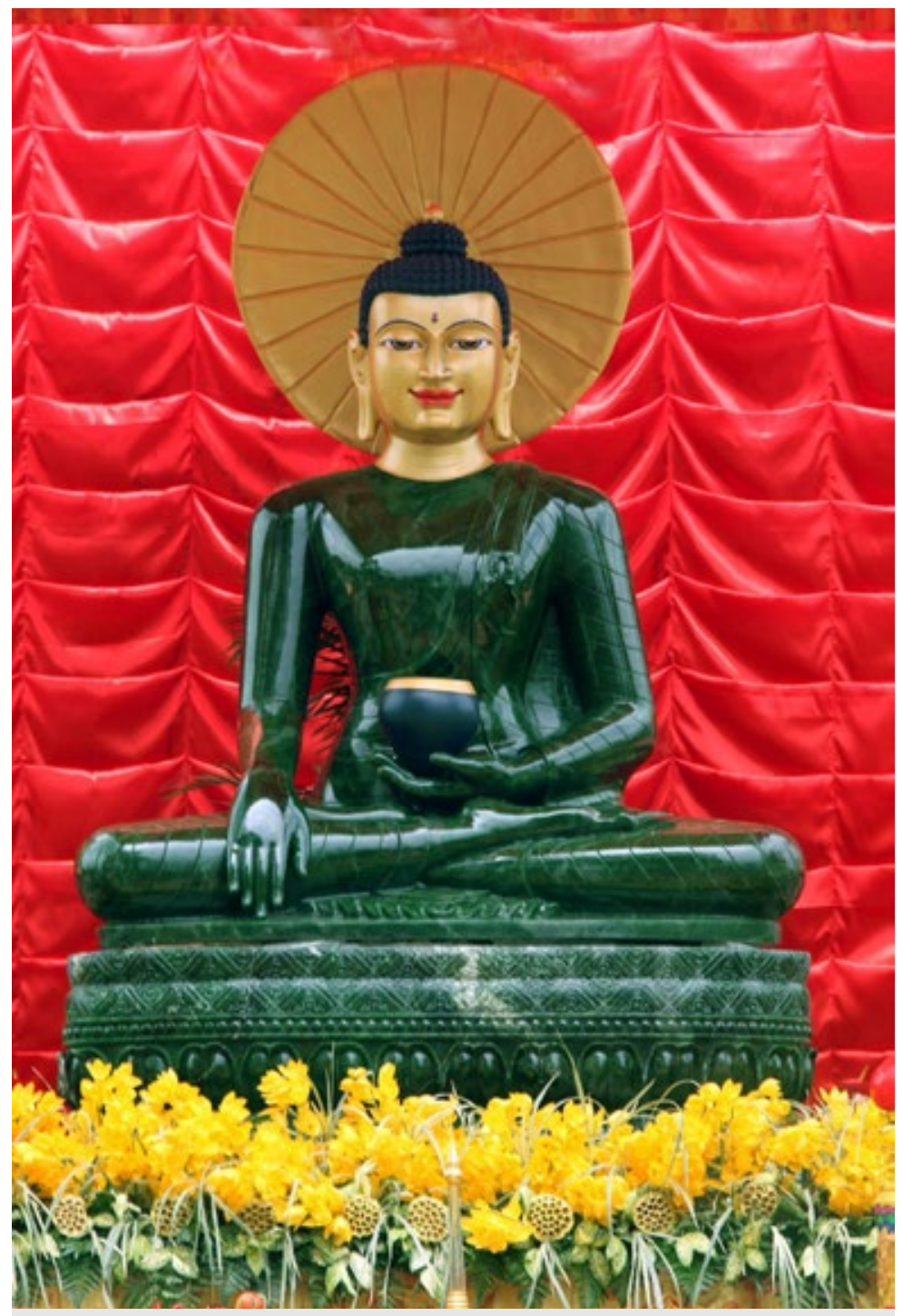

The Jade Buddha for Universal Peace, 2009

Numerous photographs appear to reveal what adherents are calling "mandala lights" around the Jade Buddha for Universal Peace as it makes its way around the world on a tour of Buddhist temples, monasteries, town squares, and museums. Some say the mysterious luminescent globes around the figure are brief glimpses of Buddhas and their pure lands, which interpenetrate with our own world but can only be seen by the enlightened. Others say it's merely glare.

Since March of 2009, the large jade statue has visited dozens of cities in Asia, Australia, North America, and Europe, attracting considerable crowds. Its official website claims that over 7,000,000 people have come to view it. The mayor of Worcester, 
Massachusetts declared May 22, 2010 Jade Buddha for Universal Peace Day. Events around the image combine solemn ceremony with an atmosphere of family-fun carnival or multicultural fair, drawing local people of Asian ethnicity, art lovers, spiritual seekers, and curious onlookers.

The eight-foot tall, 4.5 ton Buddha was carved from a rare giant boulder of gemstonequality jade discovered in Canada in 2000. A Californian jade jewelry maker who knew about the boulder telephoned Ian Green, an Australian already involved in an even more massive Buddhist building project, the Great Stupa of Universal Compassion near Bendigo, Australia. Green flew to North America, viewed the boulder, then consulted his Buddhist teacher, Lama Zopa Rinpoche, a well known Nepalese lama and spiritual director of the stupa project. According to Green, Lama Zopa had had a vision that this boulder would become a Buddha that would "illuminate the world"; he told Green to have the sculpture made.

With singleness of purpose, Green pursued funding to purchase the boulder and commission the work. The international effort to complete the project included Thai and Australian sculptors, a Nepalese thanka painter, and donors from around the world. Sales of smaller jade Buddhas made from carving fragments helped fund the project. After five years of fund-raising to make a deposit on the boulder, it was shipped to Thailand where master carvers fashioned the rock into the largest jade Buddha in the world. Completed in 2008 and now valued at \$5 million, it was consecrated in 2009 at the Sydney Entertainment Centre in Sydney, Australia. After the Jade Buddha's world tour is over it will take up permanent residency in the Great Stupa of Universal Compassion.

In the West, where the "material" is often pitted against the "religious" and where Buddhism is often seen as detached from the material world, it may be puzzling to some that such an incredible amount of time, effort, and money have been poured into the construction and display of such an image. Buddhist media outlets that cater to Western converts, in fact, have ignored the statue and its publicity.

The many and various descriptions of what the Jade Buddha is and what its display is meant to accomplish may also be confusing in some contexts. On the internet and among people in the throngs that view it, we find it described as a "great work of art" and a "symbol of peace." According to the official website, "the purpose of exhibiting the Jade Buddha around the world is for everyone, irrespective of their religion, to take a moment to reflect upon peace.... We hope that such positive inspiration will bring joy and motivation in the lives of those who are able to see the Jade Buddha." Even more enthusiastically, another part of the website says that it will "illuminate the world and bring inconceivable peace and happiness and help prevent the destruction that is happening in so much of the world, including war."2 Devotees have described it as a holy presence through which people can receive blessings and karmic merit. Some claim that miracles have occurred in its presence.

Thinking of this figure as a work of art or a symbol of peace is not so unusual for many 


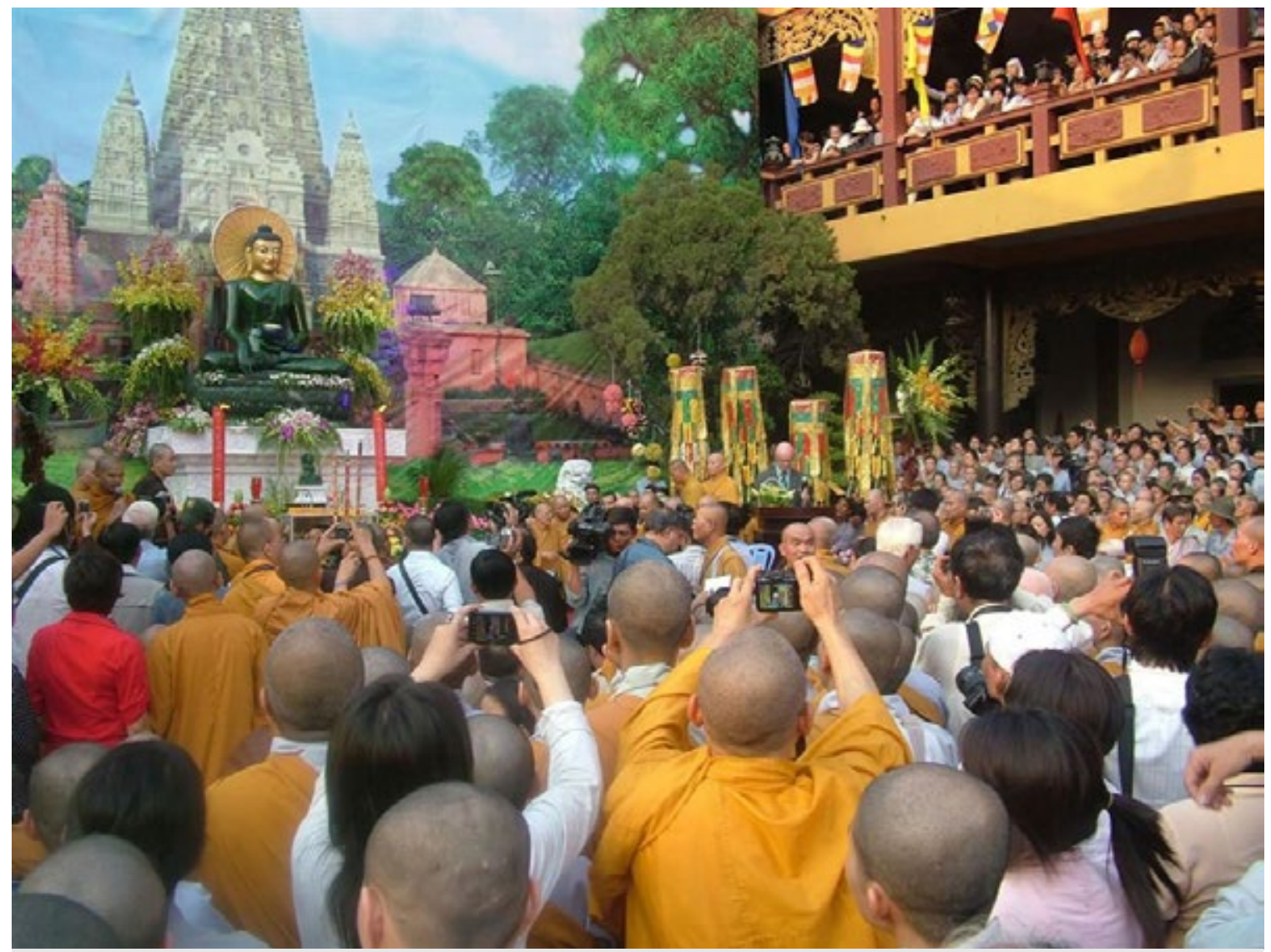

The Jade Buddha on tour

in the West. Some of the website descriptions go further however, suggesting that the Jade Buddha has agency-it blesses, helps prevent destruction, brings peace, brings miracles. Such ideas would not be unusual for many in Asia. There is a long tradition of statues being understood as extensions of sacred beings. Consecration rituals going back to the pre-common era invite such beings to embody material objects.

Moreover Buddhists and Hindus, past and present, place special importance on seeing the sacred image. The Indian tradition of "taking darshan"-seeing, and being seen by, the holy person or representation thereof-characterizes contemporary practice as well as past experience. One can take darshan with living teachers, ancient statues, glossy posters of Hindu deities, or Buddhas on a computer screen. While in most cases devotees go to the deities for darshan, gods and goddesses are often brought out to the people during festivals, taking carriage rides around the town or district and participating in tours like the one upon which the Jade Buddha has embarked. Our word "juggernaut" comes from Jagannath, a name of Vishnu, and refers to the chaotic festival in the Indian city of Puri when throngs of devotees cart the main temple's statue through the streets for all to view. Similar practices can be documented among the observant, past and present, in other religious traditions as well.

Today a complex network of barges, cranes, trucks, steel cages, and packing materials make it possible for the Jade Buddha for Universal Peace to extend the traditional tour 
of the city to a tour of the world.

(C) David L. McMahan

\section{Citation Guide}

1. David L. McMahan, "The Jade Buddha for Universal Peace," Object Narrative, in Conversations: An Online Journal of the Center for the Study of Material and Visual Cultures of Religion (2014), doi:10.22332/con.obj.2014.11

McMahan, David L. "The Jade Buddha for Universal Peace." Object Narrative. In Conversations: An Online Journal of the Center for the Study of Material and Visual Cultures of Religion (2014). doi:10.22332/con.obj.2014.11

\section{Notes}

1. Website of the Jade Buddha for Universal Peace, 2011. perma.cc/oTNaLgHfkLf

2. Ian Green, "The Jade Buddha Story, Part Two: The creation," Website of the Jade Buddha for Universal Peace, 2011. perma.cc/oYHwMmZgHuG

\section{Yale}

